\title{
A validated stability-indicating HPLC method for the simultaneous determination of pheniramine maleate and naphazoline hydrochloride in pharmaceutical formulations
}

Taomin Huang ${ }^{1 *}$, Nianzu Chen ${ }^{1}$, Donglei Wang ${ }^{1}$, Yonghua Lai ${ }^{1}$ and Zhijuan Cao ${ }^{2 *}$

\begin{abstract}
Background: A simple, rapid, and accurate stability-indicating reverse phase liquid chromatographic method was developed and validated for the simultaneous determination of pheniramine maleate and naphazoline hydrochloride in bulk drugs and pharmaceutical formulations.

Results: Optimum chromatographic separations among pheniramine maleate, naphazoline hydrochloride and stress-induced degradation products have been achieved within 10 minutes by using an Agilent zorbax eclipse XDB C18 column $(150 \mathrm{~mm} \times 4.6 \mathrm{~mm}, 5 \mu \mathrm{m})$ as the stationary phase with a mobile phase consisted of $10 \mathrm{mM}$ phosphate buffer $\mathrm{pH} 2.8$ containing $0.5 \%$ triethlamine and methanol $(68: 32, \mathrm{v} / \mathrm{v})$ at a flow rate of $1 \mathrm{~mL} \mathrm{~min}^{-1}$. Detection was performed at $280 \mathrm{~nm}$ using a diode array detector. Theoretical plates for pheniramine maleate and naphazoline hydrochloride were calculated to be 6762 and 6475, respectively. The method was validated in accordance with ICH guidelines with respect to linearity, accuracy, precision, robustness, specificity, limit of detection and quantitation. Regression analysis showed good correlations $\left(R^{2}>0.999\right)$ for pheniramine maleate in the concentration range of 150-1200 $\mathrm{mg} \mathrm{mL}^{-1}$ and naphazoline hydrochloride in 12.5-100 $\mathrm{g} \mathrm{mL}^{-1}$. The method results in excellent separation of both the analytes and degradation products. The peak purity factor is $\geq 980$ for both analytes after all types of stress, indicating complete separation of both analyte peaks from the stress induced degradation products.
\end{abstract}

Conclusions: Overall, the proposed stability-indicating method was suitable for routine quality control and drug analysis of pheniramine maleate and naphazoline hydrochloride in pharmaceutical formulations.

Keywords: Liquid chromatography, Method validation, Pheniramine maleate, Naphazoline hydrochloride,

Degradation products

\section{Introduction}

Pheniramine maleate $(p K a=9.3)$, chemically known as $\mathrm{N}$, $\mathrm{N}$-Dimethyl-3-phenyl-3-(2-pyridyl) propylamine hydrogen maleate $\left(\mathrm{C}_{16} \mathrm{H}_{20} \mathrm{~N}_{2} \cdot \mathrm{C}_{4} \mathrm{H}_{4} \mathrm{O}_{4}\right)$, is an antihistamine $\mathrm{H}_{1}$ receptor antagonist by inhibiting the effect of histamine on capillary permeability, gastric secretion, and contraction of bronchiolar and gastrointestinal smooth muscle [1,2]. Recently, Kerem Karaman et al. reported that pheniramine maleate could be used as an antihistaminic for

\footnotetext{
*Correspondence: taominhuang@126.com; zjcao@fudan.edu.cn 'Department of Pharmacy, Eye Ear Nose Throat Hospital of Fudan University, Fenyang Road, No. 83, Shanghai 200031, People's Republic of China ${ }^{2}$ School of Pharmacy, Fudan University, Zhangheng Road, No. 826, Shanghai 201203, People's Republic of China
}

the symptomatic relief of a hypersensitivity reaction, such as the acute ocular allergic reaction and shortduration, mild to moderate, intermittent ocular allergy [3]. Naphazoline hydrochloride $(p K a=10.8)$, chemically designated as 2-(1-naphthylmethyl)-2-imidazoline hydrochloride $\left(\mathrm{C}_{14} \mathrm{H}_{14} \mathrm{~N}_{2} \cdot \mathrm{HCl}\right)$, is a sympathomimetric agent with marked $\alpha$-adrenergic activity and is a relatively long-lasting vasoconstrictor with a rapid action in reducing swelling when applied to the mucous membrane [4]. Figure 1 shows the structure formulae of pheniramine maleate and naphazoline hydrochloride. A novel fixed dose combination of pheniramine maleate and naphazoline hydrochloride is approved and available in 


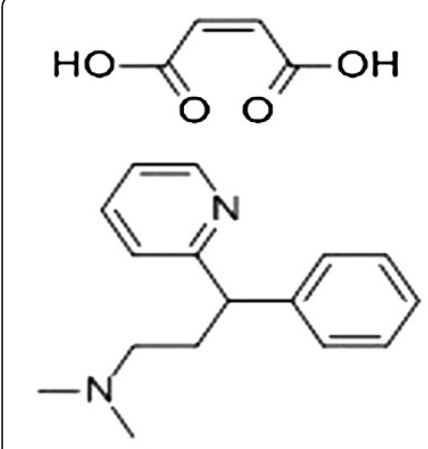

(A)

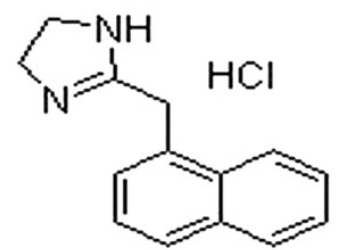

(B)
Figure 1 The structural formulae of $(A)$ pheniramine maleate and (B) naphazoline hydrochloride.

the market, indicating that it can relieve redness, burning, irritation, and dryness of the eyes caused by wind, sun, and other minor irritants.

Various techniques have been reported for the determination of pheniramine maleate and naphazoline hydrochloride, respectively. Among them, the methods for the detection of pheniramine maleate included ultra-violet spectrophotometry [5], thin-layer chromatography-densitometry [6], and high performance liquid chromatography, etc. $[7,8]$. Naphazoline hydrochloride in pharmaceutical formulations or biological fluids either alone or in combination with other drugs was also detected by many methods, such as spectrophotometry $[9,10]$, gas chromatography [11], high performance liquid chromatography [12-15], capillary electrophoresis [16-18], atomic emission and atomic absorption spectrometry [19], electrochemical method [20] and luminescence method [21,22]. However, in some extent, the above-described methods are limited in either low sensitivity or specificity. Furthermore, extensive survey revealed that no stability-indicating high performance liquid chromatography (HPLC) method has been reported including major pharmacopoeias such as USP, EP, JP and BP for the simultaneous determination of these two drugs in pharmaceutical formulation. Therefore, it is necessary to develop and validate a simple and accurate stability-indicating HPLC method for simultaneous determination of both drugs and their degradation products in pharmaceutical formulations.

\section{Results and discussion}

\section{Optimization of the Chromatographic System}

There were two peaks of pheniramine maleate in the chromatography. Maleate is a dicarboxylic acid. Its ionization constant were $K_{1}=1.0 \times 10^{-2}$ and $K_{2}=5.5 \times 10^{-7}$. Pheniramine maleate was ionized pheniramine positive ion and maleate negative ion in the mobile phase. The maleate negative ion was in the front (about $1.7 \mathrm{~min}$ ) and pheniramine positive ion was behind the maleate peak (about
$3.0 \mathrm{~min}$ ) [Figure 2]. The content of pheniramine maleate was calculated according to the peak area of pheniramine (about $3.0 \mathrm{~min}$ ) in this study.

The main objective of our work was to develop a stability-indicating HPLC method for determination of pheniramine maleate and naphazoline hydrochloride within a short run time between 3 to $10 \mathrm{~min}$ and symmetry between 0.80 and 1.20 . The $p K a$ of pheniramine maleate and naphazoline hydrochloride are 9.3 and 10.8 with a UV spectral maximum response at $262 \mathrm{~nm}$ and $280 \mathrm{~nm}$, respectively. In the commercial eye drops in the market, the content of naphazoline hydrochloride $\left(0.25 \mathrm{mg} \cdot \mathrm{mL}^{-1}\right)$ is far lower than that of pheniramine maleate $\left(3 \mathrm{mg} \cdot \mathrm{mL}^{-1}\right)$. Therefore, the wavelength of $280 \mathrm{~nm}$ was used for LC detection.

Both pheniramine and naphazoline hydrochloride have high carbon to heteroatom ratio and have conjugated bond. Therefore, they can be separated through C18 stationary phase based mainly on their overall hydrophobicity. Pheniramine and naphazoline hydrochloride can also be separated using phenyl-Hexyl stationary phase considering their $\pi$ electrons involving $\pi-\pi$ interactions. Finally, both drugs also contain polar functional groups. So they may be separated using cyano stationary phase.

\section{Optimization of mobile phase, $\mathrm{pH}$ and stationary phase}

The stationary and mobile phases play an important role on peak shape, symmetry, theoretical plates and resolution. To obtain symmetrical peaks with better resolution and no peak impurity, various chromatographic conditions was investigated and optimized for the determination of pheniramine maleate and naphazoline hydrochloride, such as mobile phase with different composition, $\mathrm{pH}$ and stationary phases with different packing material etc. That is, attempts were made by using three HPLC columns (Agilent zorbax eclipse XDB C18, Agilent Eclipse Plus Phenyl-Hexyl, and Dikma Platisil Cyano) with different mobile phase compositions and ratios. In all of the preceding columns, broad peaks were obtained for pheniramine and naphazoline hydrochloride by using different ratios (40:60, 50:50, 60:40, 70:30, $80: 20$ ) of methanol and water. No improvement of peak shape was obtained even when the temperature of column was enhanced to $40^{\circ} \mathrm{C}$. The broad peak may be attributed to low polarity of the mobile phase. So different concentration (10 mM, $20 \mathrm{mM}, 50 \mathrm{mM}$ ) of phosphate buffer was added to improve polarity of the mobile phase. The peak was narrowed but the peak symmetry was still not satisfactory. Then triethylamine (as silanol blocker) was added to the water phase, it was demonstrated that $10 \mathrm{mM}$ phosphate buffer containing $0.5 \% \mathrm{v} / \mathrm{v}$ triethylamine was best for the improvement of peak shape. Moreover, buffer $\mathrm{pH}$ was found to be critical in the analytes separation and was extensively studied in method 


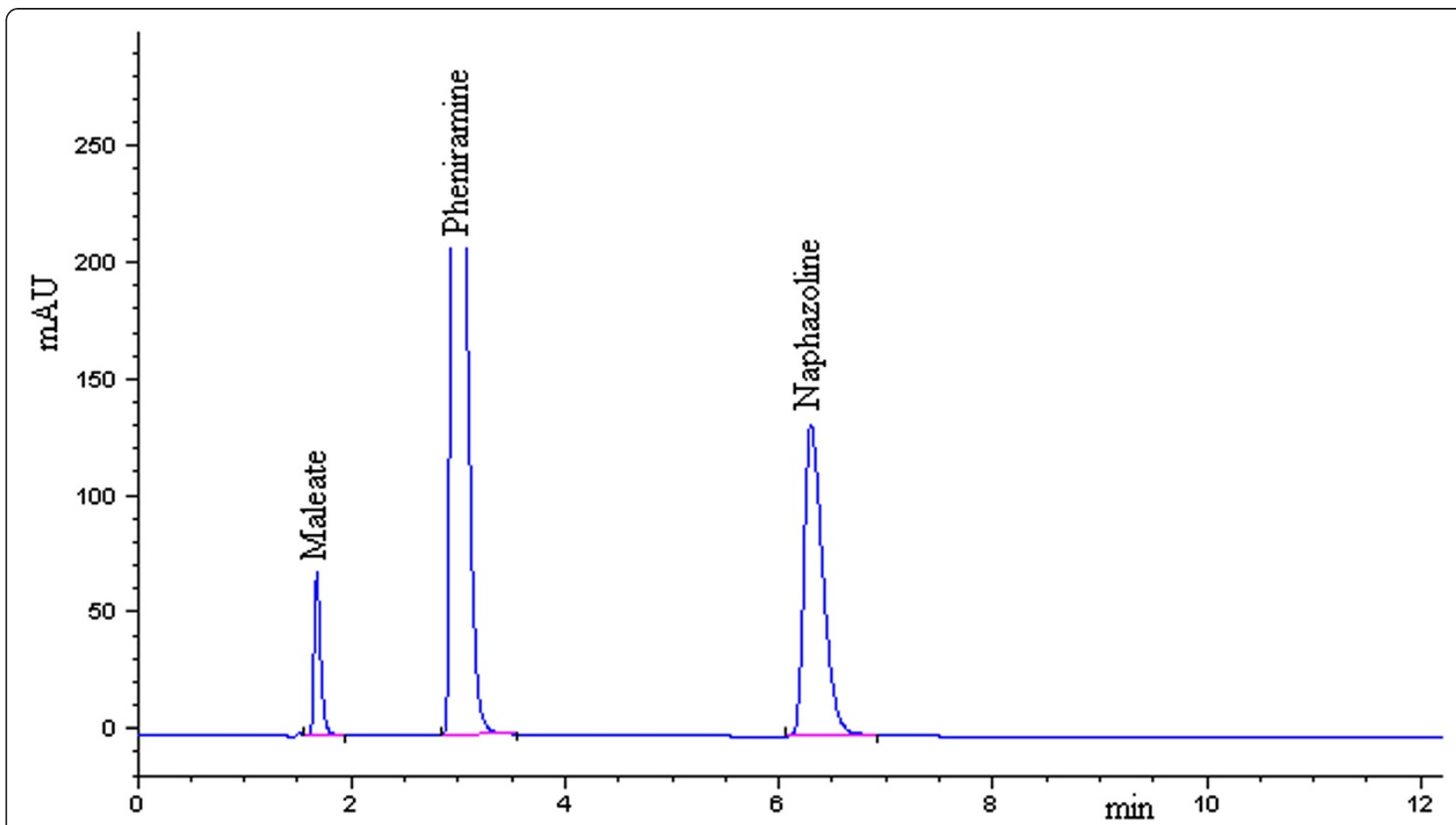

Figure 2 Chromatogram for separation of pheniramine maleate and naphazoline hydrochloride in pharmaceutical formulations.

optimization. The effect of $\mathrm{pH}$ on retention was related with the ionization form of these solutes. In the attempt to investigate the effect of the mobile phase $\mathrm{pH}$ on the retention time and resolution of two substrates, the $\mathrm{pH}(2.8$, 4.0, 5.0 and 6.0) was employed for this assay while keeping the other chromatographic parameters unchanged, i.e., Agilent zorbax eclipse XDB C18 column and the fixed mobile phase composition of $10 \mathrm{mM}$ phosphate buffer containing $0.5 \% \mathrm{v} / \mathrm{v}$ triethlamine: methanol $(68: 32, v / v)$. As demonstrated in Table 1, a buffer $\mathrm{pH}$ of 2.8 was found to be optimal with narrow peak, resolution $\left(R_{s} \geq 3\right)$ and analysis time $\left(t_{R}\right.$ between $3 \sim 10 \mathrm{~min}$ ), which was then selected for the following experiments.

Following that, under the optimized mobile phase of methanol and $10 \mathrm{mM}$ phosphate buffer with $0.5 \% \mathrm{v} / \mathrm{v}$ triethlamine $(\mathrm{pH} 2.8)(68: 32, v / v)$, the experiments were performed on three different stationary phase. Highly symmetrical and sharp peaks of pheniramine and naphazoline hydrochloride were obtained on Agilent zorbax eclipse XDB C18 column (with better resolution, peak shapes, theoretical plates) as compared to other stationary phases (Agilent Eclipse Plus Phenyl-Hexyl, and

Table 1 pH Optimization of phosphate buffer

\begin{tabular}{|c|c|c|c|c|}
\hline Mobile phase & Theoretical plates (N) & Symmetry & Resolution (R) & Peak shape \\
\hline \multicolumn{5}{|c|}{ Methanol: Phosphate buffer, pH 2.8 (68:32) } \\
\hline Pheniramine & 6762 & 0.91 & 7.75 & +++ \\
\hline Naphazoline hydrochloride & 6475 & 0.93 & & +++ \\
\hline \multicolumn{5}{|c|}{ Methanol: Phosphate buffer, pH 4 (68:32) } \\
\hline Pheniramine & 1319 & 0.26 & 4.13 & - \\
\hline Naphazoline hydrochloride & 4737 & 0.43 & & +++ \\
\hline \multicolumn{5}{|c|}{ Methanol: Phosphate buffer, pH 5 (68:32) } \\
\hline Pheniramine & 6731 & 0.54 & 0.98 & +++ \\
\hline Naphazoline hydrochloride & 1325 & 0.24 & & - \\
\hline \multicolumn{5}{|c|}{ Methanol: Phosphate buffer, pH 6 (68:32) } \\
\hline Pheniramine & 6499 & 0.54 & 2.75 & +++ \\
\hline Naphazoline hydrochloride & 1683 & 0.23 & & 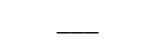 \\
\hline
\end{tabular}


Dikma Platisil Cyano), which was used in subsequent experiments.

\section{Method validation}

The developed chromatographic method was validated using ICH guidelines [23,24]. Validation parameters included linearity, accuracy, precision, robustness, specificity, LOD and LOQ.

Linearity was verified by triplicate analysis of different concentrations. As a result, the linear regression equation was found to be $Y=5.0985 X+23.4917\left(R^{2}=0.9993, n=6\right.$, $\left.150-1200 \mu \mathrm{g} \mathrm{mL}^{-1}\right)$ for pheniramine and $Y=28.3892 X+$ $18.8795\left(R^{2}=0.9999, n=6,12.5-100 \mu \mathrm{g} \mathrm{mL}^{-1}\right)$ for naphazoline hydrochloride, respectively. In which, $\mathrm{Y}$ was the dependent. variable, $\mathrm{X}$ was independent variable, 5.0985 and 28.3892 were slopes which showed change in dependent $(\mathrm{Y})$ variable per unit change in independent (X) variable; 23.4917 and 18.8795 were the $Y$-intercept i.e., the value of $\mathrm{Y}$ variable when $\mathrm{X}=0$.

Based on a signal-to-noise ratio of 3:1, LOD was found to be 0.1 and $0.02 \mu \mathrm{g} \mathrm{mL}{ }^{-1}$ for pheniramine maleate and naphazoline hydrochloride, respectively. LOQ with a signal-to-noise of 10:1 was found to be $0.3 \mu \mathrm{g} \mathrm{mL} \mathrm{m}^{-1}$ for pheniramine maleate and $0.07 \mu \mathrm{g} \mathrm{mL} \mathrm{m}^{-1}$ for naphazoline hydrochloride, respectively.

Accuracy of the developed method was determined by analyzing samples before and after the addition of known amounts of pheniramine maleate and naphazoline hydrochloride. The acceptable recovery was set as between $97.0 \%$ and $103.0 \%$ [Table 2]. The developed analytical method had good accuracy with overall recovery rates in the range of $97.8 \%-102.1 \%$ for all compounds with RSDs below $1.3 \%$, indicating that the proposed method was to be highly accurate and suitable for intended use.

The precision was evaluated by analyzing the standard solutions of pheniramine maleate and naphazoline hydrochloride at three concentrations under the optimal conditions. It was considered at two levels: five times in one day for repeatability (intra-days) and on three consecutive days for intermediate precision (inter-days). The corresponding results were expressed as the relative

Table 2 Accuracy of the proposed HPLC method

\begin{tabular}{|c|c|c|c|c|}
\hline Drugs & $\begin{array}{c}\text { Spiked } \\
\text { concentration } \\
\left(\mu \mathrm{g} \mathrm{mL}^{-1}\right)\end{array}$ & $\begin{array}{c}\text { Measured } \\
\text { concentration } \\
\left(\mu \mathrm{g} \mathrm{mL}^{-1}\right) \pm \mathrm{SD}\end{array}$ & $\begin{array}{c}\text { Accuracy } \\
(\%)\end{array}$ & $\begin{array}{l}\text { RSD } \\
\text { (\%) }\end{array}$ \\
\hline \multirow[t]{3}{*}{ Pheniramine } & 150.0 & $151.2 \pm 1.7$ & 100.9 & 1.2 \\
\hline & 600.0 & $612.4 \pm 6.1$ & 102.1 & 1.0 \\
\hline & 1200.0 & $1187.6 \pm 15.6$ & 99.0 & 1.3 \\
\hline \multirow{3}{*}{$\begin{array}{l}\text { Naphazoline } \\
\text { hydrochloride }\end{array}$} & 12.5 & $12.6 \pm 0.1$ & 101.1 & 1.0 \\
\hline & 50.0 & $49.8 \pm 0.6$ & 99.6 & 1.2 \\
\hline & 100.0 & $97.8 \pm 0.6$ & 97.8 & 0.6 \\
\hline
\end{tabular}

Table 3 Intra-day and Inter-day precision of the proposed HPLC method $(n=5)$

\begin{tabular}{llll}
\hline Drugs & $\begin{array}{l}\text { Actual } \\
\text { concentration } \\
\left(\mu \mathbf{~ m L}^{-1}\right)\end{array}$ & $\begin{array}{l}\text { Intra-day } \\
\text { precision } \\
\text { Measured } \\
\text { concentration } \pm \\
\text { SD; RSD (\%) }\end{array}$ & $\begin{array}{l}\text { Inter-day } \\
\text { precision } \\
\text { Measured } \\
\text { concentration } \pm \\
\text { SD; RSD (\%) }\end{array}$ \\
\hline Pheniramine & 150.0 & $147.8 \pm 1.1 ; 1.0$ & $147.6 \pm 1.3 ; 1.2$ \\
& 600.0 & $608.5 \pm 2.4 ; 0.4$ & $607.0 \pm 1.3 ; 1.0$ \\
Naphazoline & 12.5 & $1194.7 \pm 2.7 ; 0.3$ & $1197.6 \pm 7.4 ; 0.6$ \\
hydrochloride & 50.0 & $12.6 \pm 0.05 ; 0.4$ & $12.5 \pm 0.1 ; 0.9$ \\
& 100.0 & $50.3 \pm 0.3 ; 0.5$ & $50.4 \pm 0.2 ; 0.4$ \\
& & $100.1 \pm 0.4 ; 0.4$ & $100.4 \pm 0.5 ; 0.5$ \\
\hline
\end{tabular}

standard deviation (RSD) and mean recovery of a series of measurements. The calculated RSD values of the intra- and inter-day assay were $<1.0 \%$ and $1.2 \%$, respectively [Table 3]. The results also demonstrated that pheniramine maleate and naphazoline hydrochloride were stable in solution.

Robustness was validated by slightly varying the chromatographic conditions. In all of the deliberately varied chromatographic conditions (different flow rate, buffer composition and buffer $\mathrm{pH}$ ), no obvious effect on the chromatographic parameters was observed [Tables 4 and 5].

Specificity was investigated by using photodiode array detection to ensure the homogeneity and evaluate purity of analyte peak. We found no interference of diluents and excipients firstly, and then the peak purity values were evaluated at different stress conditions (acid, base, oxidation, thermal and photolytic) for pheniramine maleate and naphazoline hydrochloride in formulation. As shown in Figure 3, several degradation products were detected, but had no influence on the main ingredients. The peak purity factor was more than 980 for drug product (Table 6), which further confirmed the specificity of this method.

\section{Table 4 Robustness of pheniramine}

\begin{tabular}{|c|c|c|c|c|}
\hline $\begin{array}{l}\text { Chromatographic } \\
\text { condition }\end{array}$ & Assay \% & $t_{R}(\min )$ & $\begin{array}{l}\text { Theoretical } \\
\text { plates }\end{array}$ & Symmetry \\
\hline Flow rate $\left(0.9 \mathrm{~mL} \mathrm{\textrm {min } ^ { - 1 } )}\right.$ & 103.4 & 3.734 & 6623 & 0.89 \\
\hline Flow rate $\left(1 \mathrm{~mL} \mathrm{~min}{ }^{-1}\right)$ & 101.2 & 3.013 & 6762 & 0.90 \\
\hline Flow rate $\left(1.1 \mathrm{~mL} \mathrm{~min}^{-1}\right)$ & 99.5 & 2.910 & 6745 & 0.91 \\
\hline Buffer: Methanol (70:30) & 99.2 & 4.136 & 6612 & 0.87 \\
\hline Buffer: Methanol (68:32) & 100.7 & 3.013 & 6523 & 0.88 \\
\hline Buffer: Methanol (65:35) & 99.6 & 2.956 & 6524 & 0.86 \\
\hline Buffer (pH 2.6) & 101.7 & 2.990 & 6456 & 0.92 \\
\hline Buffer (pH 2.8) & 101.9 & 3.073 & 6346 & 0.85 \\
\hline Buffer (pH 3.0) & 100.9 & 3.360 & 6678 & 0.86 \\
\hline
\end{tabular}


Table 5 Robustness of naphazoline hydrochloride

\begin{tabular}{lllll}
\hline $\begin{array}{l}\text { Chromatographic } \\
\text { condition }\end{array}$ & Assay $\%$ & $\mathbf{t}_{\mathbf{R}}(\mathbf{m i n})$ & $\begin{array}{l}\text { Theoretical } \\
\text { plates }\end{array}$ & Symmetry \\
\hline Flow rate $\left(0.9 \mathrm{~mL} \mathrm{~min}^{-1}\right)$ & 101.5 & 6.565 & 6534 & 0.91 \\
Flow rate $\left.(1 \mathrm{~mL} \mathrm{~min})^{-1}\right)$ & 99.9 & 6.154 & 6745 & 0.93 \\
Flow rate $\left(1.1 \mathrm{~mL} \mathrm{~min}^{-1}\right)$ & 103.6 & 5.331 & 6521 & 0.88 \\
Buffer: Methanol (70:30) & 99.7 & 6.944 & 6346 & 0.90 \\
Buffer: Methanol (68:32) & 99.2 & 6.154 & 6351 & 0.89 \\
Buffer: Methanol (65:35) & 98.1 & 5.681 & 6566 & 0.86 \\
Buffer (pH 2.6) & 100.9 & 5.764 & 6812 & 0.85 \\
Buffer (pH 2.8) & 101.4 & 6.148 & 6745 & 0.89 \\
Buffer (pH 3.0) & 100.2 & 6.145 & 6625 & 0.87 \\
\hline
\end{tabular}

\section{Results of forced degradation study}

All the stress conditions applied were enough to degrade two ingredients. Pheniramine was degraded up to $95.5 \%$ and naphazoline hydrochloride was degraded up to $78.5 \%$ when $5 \mathrm{M} \mathrm{HCl}$ was used. Pheniramine maleate was degraded up to $65.3 \%$ and naphazoline hydrochloride was degraded up to $44.9 \%$ when $5 \mathrm{M} \mathrm{NaOH}$ was used. Pheniramine maleate was degraded up to $84.9 \%$ and naphazoline hydrochloride was degraded up to $76.0 \%$ under oxidative stress. Pheniramine maleate was stable and naphazoline hydrochloride was degraded up to $94.3 \%$ for $240 \mathrm{~h}$ under thermal stress $\left(40^{\circ} \mathrm{C}\right)$. Pheniramine maleate was stable and naphazoline hydrochloride was degraded up to $68.4 \%$ for $240 \mathrm{~h}$ under thermal stress (dry heat). Both pheniramine maleate and naphazoline hydrochloride were not degraded substantial under photolytic stress. From these stress studies it was thus concluded that pheniramine maleate and naphazoline hydrochloride were not stable in basic, acidic, oxidative and thermal conditions. The results of stress studies are shown in Table 6.

Aside from the percentage degradation of each ingredient, a number of degradation products (DE) were produced under acidic (3 degradation peaks with DE 3 as major degradation peak), basic (3 degradation peaks with DE 3 as major degradation peak), oxidative (5 degradation peaks with DE 1 as major degradation peak), thermal stress (dry heat) (2 degradation peaks with DE 2 as major degradation peak), photolytic stress (1 degradation peak). The developed method effectively separated the degradation products ( 3 degradation peaks under acidic stress, 3 impurity peaks under basic stress, 5 impurity peaks under oxidative stress, 2 impurity peaks under dry heat stress) from analyte peaks (Figure 3). Therefore, the developed method can be considered highly specific for intended use.

\section{Comparing the results with degradation of commercial eye drops sample solution}

The degradation results of commercial eye drops sample solution were illustrated in Table 7 . The stability results were in conformity with that in stock solution, which demonstrated that the developed method could be used to analyze pheniramine maleate and naphazoline hydrochloride in pharmaceutical formulation.

\section{Application of the developed method}

Application of the developed method was checked by analyzing pheniramine maleate and naphazoline hydrochloride in commercially available pharmaceutical formulations. The results are provided in Table 8 which showed high percentage recoveries and low RSD (\%) values for these two analytes.

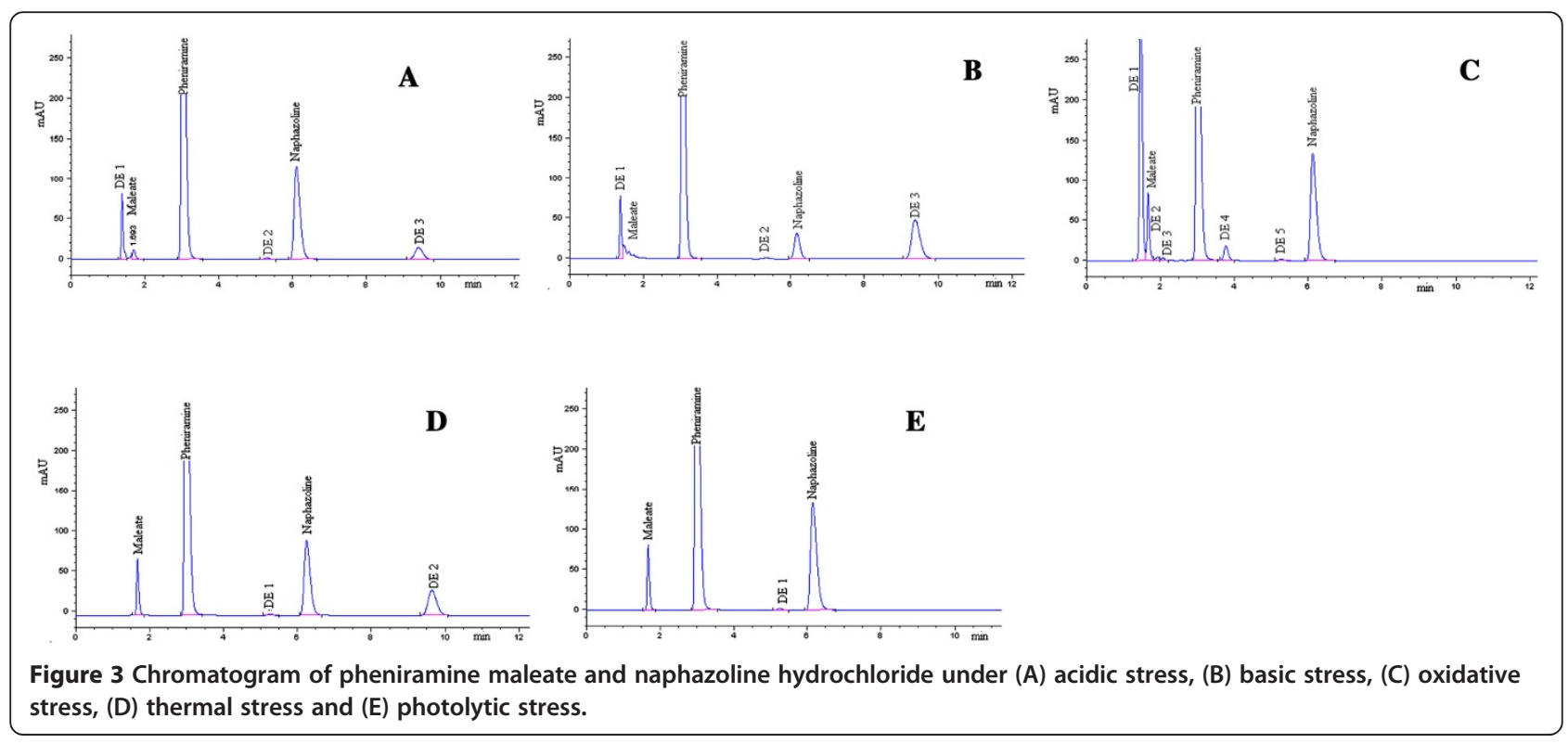


Table 6 Stress testing results of pheniramine and naphazoline hydrochloride in stock solution

\begin{tabular}{llllll}
\hline $\begin{array}{l}\text { Nature of } \\
\text { stress }\end{array}$ & Storage conditions & Time $(\mathbf{h})$ & $\begin{array}{l}\text { Amount of pheniramine } \\
\text { Remaining } \pm \text { SD (\%) }\end{array}$ & $\begin{array}{l}\text { Amount of naphazoline hydrochloride } \\
\text { Remaining } \pm \text { SD (\%) }\end{array}$ & $\begin{array}{l}\text { Extent of } \\
\text { decomposition }\end{array}$ \\
\hline $5 \mathrm{M} \mathrm{HCl}$ & $40^{\circ} \mathrm{C}$ & 24 & $95.5 \pm 0.9(\mathrm{PP}=999.213)$ & $78.5 \pm 3.8(\mathrm{PP}=999.412)$ & Substantial \\
$5 \mathrm{M} \mathrm{NaOH}$ & $40^{\circ} \mathrm{C}$ & 2 & $65.3 \pm 1.4(\mathrm{PP}=999.346)$ & $44.9 \pm 2.6(\mathrm{PP}=999.015)$ & Substantial \\
$6 \% \mathrm{H}_{2} \mathrm{O}_{2}$ & $40^{\circ} \mathrm{C}$ & 24 & $84.9 \pm 1.6(\mathrm{PP}=999.803)$ & $76.0 \pm 1.5(\mathrm{PP}=999.711)$ & Substantial \\
Thermal & $40^{\circ} \mathrm{C}$ & 120 & $98.2 \pm 1.6(\mathrm{PP}=999.872)$ & $102.5 \pm 1.0(\mathrm{PP}=999.784)$ & None \\
& $40^{\circ} \mathrm{C}$ & 240 & $99.1 \pm 1.3(\mathrm{PP}=999.423)$ & $94.3 \pm 1.2(\mathrm{PP}=999.651)$ & Substantial \\
Dry heat & $105^{\circ} \mathrm{C}$ & 7 & $99.2 \pm 2.9(\mathrm{PP}=999.903)$ & $68.4 \pm 1.9(\mathrm{PP}=999.806)$ & Substantial \\
Photolytic & 1.2 million lux hours and $200 \mathrm{~W} \mathrm{~h} / \mathrm{m}^{2}$ & $98.2 \pm 1.7(\mathrm{PP}=999.312)$ & $98.5 \pm 1.2(\mathrm{PP}=999.104)$ & None & \\
\hline
\end{tabular}

$n=$ Average of 3 determinations.

$\mathrm{PP}=$ peak purity factor, peak purity values in the range of $980 \sim 1000$ indicate a homogeneous peak.

\section{Conclusions}

A rapid and efficient RP-HPLC method was developed for the estimation of pheniramine maleate and naphazoline hydrochloride in pharmaceutical formulation and their degradation products. The proposed method was demonstrated to be accurate, precise, specific, sensitive, linear and robust based on method validation. Satisfactory results were obtained in separating the peaks of active pharmaceutical ingredients from the degradation products produced by forced degradation. Furthermore, the new method are cost-effective without the requirement of ion pairing and other derivatization agents, which are tend to adsorb very strongly on the stationary phase, resulting in difficulty in recovering initial column properties. Overall, the method is stability-indicating and can be used for routine analysis in quality control and any kind of stability and validation studies.

\section{Methods}

\section{Chemicals and reagents}

All chemicals were analytical grade and used as received. All solutions were prepared in Milli-Q deionized water from a Millipore water purification system (Bedford, MA, USA). Pheniramine maleate was purchased from EDQM CS30026-F67081 Strasbourg, France. Naphazoline hydrochloride with stated purify of $99.2 \%$ (lot No.100111-201104) was purchased from the National
Institute for the Control of Pharmaceuticals and Biological products, Beijing, China. Pheniramine maleate and naphazoline hydrochloride eye drops (claimed to contain $3 \mathrm{mg} \mathrm{mL}^{-1}$ pheniramine maleate and $0.25 \mathrm{mg} \mathrm{mL}^{-1}$ naphazoline hydrochloride) were obtained from S.A. Alcon-couvreur N.V., Rijksweg 14,2870, Puurs, Belgium (lot No. 10D09L,11F09H). The eye drops contains benzalkonium chloride as preservative in sterile aqueous base. Potassium dihydrogen phosphate $\left(\mathrm{KH}_{2} \mathrm{PO}_{4}\right)$ was obtained from Sinopharm Chemical Reagent Co. Ltd. (Shanghai, China). Triethlamine (HPLC grade) was obtained from Fisher scientific (New Jersey, USA). Phosphoric acid was obtained from Lingfeng Chemical Reagent Co. Ltd. (Shanghai, China). HPLC- grade methanol was obtained from TEDIA (OH, USA). Mobile phase was filtered using $0.45 \mu \mathrm{m}$ nylon filters from Millipore Co. (MA, USA).

\section{Equipment and chromatographic conditions}

Samples were analyzed on an Agilent 1100 HPLC system (Agilent Technologies, Palo Alto, CA, USA), attached with a G1311A quaternary pump, a G1312A vacuum degasser, and a G1315B DAD detector. The detector wavelength was fixed at $280 \mathrm{~nm}$ and peak areas were integrated automatically using the Hewlett-Packard Chem Station software program. Other apparatus included an ultrasound generator and a SevenEasy $\mathrm{pH}$ meter

Table 7 Stress testing results of pheniramine and naphazoline hydrochloride in commercial eye drops sample solution

\begin{tabular}{llllll}
\hline $\begin{array}{l}\text { Nature of } \\
\text { stress }\end{array}$ & Storage conditions & Time $(\mathbf{h})$ & $\begin{array}{l}\text { Amount of pheniramine } \\
\text { Remaining } \pm \text { SD (\%) }\end{array}$ & $\begin{array}{l}\text { Amount of naphazoline hydrochloride } \\
\text { Remaining } \pm \text { SD (\%) }\end{array}$ & $\begin{array}{l}\text { Extent of } \\
\text { decomposition }\end{array}$ \\
\hline $5 \mathrm{M} \mathrm{HCl}$ & $40^{\circ} \mathrm{C}$ & 24 & $93.4 \pm 0.7$ & $80.2 \pm 0.4$ & Substantial \\
$5 \mathrm{M} \mathrm{NaOH}$ & $40^{\circ} \mathrm{C}$ & 2 & $61.3 \pm 1.0$ & $48.7 \pm 1.6$ & Substantial \\
$6 \% \mathrm{H}_{2} \mathrm{O}_{2}$ & $40^{\circ} \mathrm{C}$ & 24 & $87.8 \pm 2.3$ & $72.1 \pm 1.8$ & Substantial \\
Thermal & $40^{\circ} \mathrm{C}$ & 120 & $99.2 \pm 1.1$ & $101.4 \pm 1.4$ & None \\
& $40^{\circ} \mathrm{C}$ & 240 & $98.5 \pm 1.4$ & $93.3 \pm 1.8$ & Substantial \\
Dry heat & $105^{\circ} \mathrm{C}$ & 7 & $98.6 \pm 2.4$ & $65.7 \pm 2.5$ & Substantial \\
Photolytic & $1.2 \mathrm{million}$ lux hours and $200 \mathrm{~W} \mathrm{~h} / \mathrm{m}^{2}$ & $97.6 \pm 1.9$ & $98.6 \pm 2.3$ & None \\
\hline
\end{tabular}

$n=$ Average of 3 determinations. 
Table 8 Assay results of pheniramine maleate and naphazoline hydrochloride in commercial eye drops $(n=3)$

\begin{tabular}{|c|c|c|c|c|}
\hline Batch no. & Compounds & Labled & Found & RSD (\%) \\
\hline \multirow[t]{2}{*}{ 10D09L } & Pheniramine maleate & 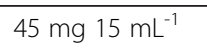 & 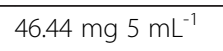 & 0.57 \\
\hline & Naphazoline hydrochloride & $3.75 \mathrm{mg} 15 \mathrm{~mL}^{-1}$ & $3.98 \mathrm{mg} 15 \mathrm{~mL}^{-1}$ & 1.04 \\
\hline \multirow[t]{2}{*}{$11 \mathrm{~F} 09 \mathrm{H}$} & Pheniramine maleate & 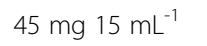 & 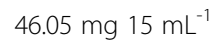 & 0.20 \\
\hline & Naphazoline hydrochloride & 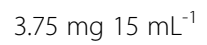 & 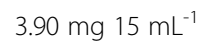 & 1.09 \\
\hline
\end{tabular}

(Mettler Toledo) that was equipped with a combined glass-calomel electrode. An electric-heated thermostatic water bath (DK-S28) and an oven (DGH-9203A) for thermal degradation were purchased from Shanghai Jing Hong Laboratory Instrument Co. Ltd (China). Photo stability studies were performed on a photo stability test chamber model Pharma 500-L (Weiss Technik UK Ltd., Germany). An Agilent zorbax eclipse C18 column $(150 \mathrm{~mm} \times 4.6 \mathrm{~mm}$ i.d., $5 \mu \mathrm{m})$ was maintained at $30^{\circ} \mathrm{C}$. The mobile phase was composed of a mixture $10 \mathrm{mM}$ phosphate buffer ( $\mathrm{pH} 2.8$ ) containing $0.5 \%$ triethlamine and methanol in the ratio of $(68: 32, v / v)$. The flow rate

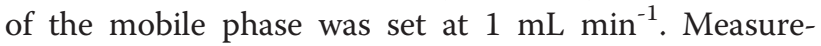
ments were made with $20 \mu \mathrm{L}$ of injection volume. For the analysis of forced degradation samples, the photodiode array detector was used in scan mode with a scan range of 200-400 $\mathrm{nm}$. The peak homogeneity was expressed in terms of peak purity factor and was obtained directly from the spectral analysis report using the above-mentioned software.

\section{Preparation of standard solution}

Standard stock solutions of pheniramine maleate $\left(3 \mathrm{mg} \mathrm{mL}^{-1}\right)$ and naphazoline hydrochloride $\left(250 \mu \mathrm{g} \mathrm{mL}^{-1}\right)$ were prepared in water. Series working solutions were diluted to the desired concentration for accuracy, precision, linearity, solution stability and robustness etc.

\section{Preparation of sample solutions}

Ophthalmic solution was transferred into a volumetric flask and diluted to requisite volume with mobile phase to obtain concentration equal to $600 \mu \mathrm{g} \mathrm{mL}^{-1}$ of phenira-

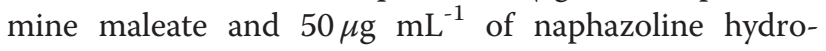
chloride. The solution was filtered through $0.45 \mu \mathrm{m}$ nylon filter before analysis.

\section{Method validation}

The proposed method was validated according to $\mathrm{ICH}$ guidelines [23] including specificity, accuracy, precision, LOD, LOQ, linearity, range and robustness.

Specificity was the ability of the method to measure the analyte from the excipients and potential impurities. The specificity of the developed method was investigated in the presence of degradation products.

The linearity test solutions were freshly prepared by diluting stock standard solutions with mobile phase. The linearity was tested at six levels ranging in 150$1200 \mu \mathrm{g} \cdot \mathrm{mL}^{-1}\left(150,300,450,600,900,1200 \mu \mathrm{g} \mathrm{mL}{ }^{-1}\right)$ for pheniramine maleate and $12.5-100 \mu \mathrm{g} \cdot \mathrm{mL}^{-1}(12.5,25$, $37.5,50,75,100 \mu \mathrm{g} \mathrm{mL}^{-1}$ ) for naphazoline hydrochloride. Each solution was prepared in triplicate. Calibration curves were plotted between the responses of peak versus analyte concentrations. The coefficient correlation, slope and intercept of calibration curve were calculated.

Accuracy of the developed method was determined by standard addition method. For this purpose, known quantities of pheniramine maleate $\left(150,600,1200 \mu \mathrm{g} \mathrm{mL}^{-1}\right)$ and naphazoline hydrochloride $\left(12.5,50,100 \mu \mathrm{g} \mathrm{mL}^{-1}\right)$ were supplemented to the sample solution previously analyzed. Then, the experimental and true values were compared [24].

The precision was tested by intra-day and inter-day precision at three level concentrations of standard mixture for pheniramine maleate $\left(150,600,1200 \mu \mathrm{g} \mathrm{mL}{ }^{-1}\right)$ and naphazoline hydrochloride $\left(12.5,50,100 \mu \mathrm{g} \mathrm{mL}^{-1}\right)$. Intra-day precision was studied on the same day $(n=5)$. And inter-day precision was determined by performing the same procedures on three consecutive days. Percentage relative standard deviation (RSD\%) for peak areas was then calculated to represent precision.

To determine the robustness of the developed method, the mobile phase composition, flow rate and $\mathrm{pH}$ of buffer solution were deliberately changed. The effect of these changes on chromatographic parameters such as retention time, symmetry and number of theoretical plates was then measured.

Limit of detection (LOD) and limit of quantitation (LOQ) values were determined at signal-to-noise $(\mathrm{S} / \mathrm{N})$ ratios of 3:1 and 10:1, respectively, by injecting a series of dilute solutions with known concentrations.

\section{Procedure for forced degradation study}

Forced degradation was carried out using different $\mathrm{ICH}$ $[25,26]$ prescribed stress conditions such thermolytic, photolytic, acid, base hydrolytic and oxidative stress conditions.

\section{Acid degradation}

For this purpose, $2 \mathrm{~mL}$ of the standard stock solution was transferred into a $10 \mathrm{~mL}$ volumetric flask. And then $2 \mathrm{~mL} 5 \mathrm{M} \mathrm{HCl}$ was added into the flask, which was kept at $40^{\circ} \mathrm{C}$ for $24 \mathrm{~h}$ in water bath [24]. After completion of 
the stress, the solution was cooled in room temperature and neutralized by using $5 \mathrm{M} \mathrm{NaOH}$ and the volume was completed up to the mark with mobile phase.

\section{Alkali degradation}

For this purpose, $2 \mathrm{~mL}$ of the standard stock solution was transferred into a $10 \mathrm{~mL}$ volumetric flask. Add $2 \mathrm{~mL}$ $5 \mathrm{M} \mathrm{NaOH}$ in the flask and keep at $40^{\circ} \mathrm{C}$ for $2 \mathrm{~h}$ in water bath. After completion of the stress, the solution was cooled in room temperature and neutralized by using $5 \mathrm{M} \mathrm{HCl}$ and diluted to the mark with mobile phase.

\section{Oxidative degradation}

For this purpose, $2 \mathrm{~mL}$ of the standard stock solution was transferred into $10 \mathrm{~mL}$ volumetric flask. Add $2 \mathrm{~mL}$ $6 \% \mathrm{H}_{2} \mathrm{O}_{2}$ added in the flask and keep at $40^{\circ} \mathrm{C}$ for $24 \mathrm{~h}$ in water bath. After completion of the stress, the solution was cooled in room temperature and diluted to the mark with mobile phase.

\section{Thermal degradation}

Thermal degradation studies were performed at two different temperatures: $40^{\circ} \mathrm{C}$ in water bath and $105^{\circ} \mathrm{C}$ in oven (dry heat thermolysis). For thermal degradation at $40^{\circ} \mathrm{C}, 2 \mathrm{~mL}$ of the standard stock solution was transferred into $10 \mathrm{~mL}$ volumetric flask and kept at $40^{\circ} \mathrm{C}$ in water bath for $120 \mathrm{~h}$ and $240 \mathrm{~h}$. After completion of the stress, the solution was cooled in room temperature and the volume was completed up to the mark with mobile phase. For dry heat thermolysis, $150 \mathrm{mg}$ pheniramine maleate and $12.5 \mathrm{mg}$ naphazoline hydrochloride were mixed in Petri dish at $105^{\circ} \mathrm{C}$ for $7 \mathrm{~h}$. After completion of the stress, the powder mixture was dissolved and diluted to $50 \mathrm{~mL}$ with mobile phase. $2 \mathrm{~mL}$ of this solution was further diluted to $10 \mathrm{~mL}$ with mobile phase.

\section{Photolytic degradation}

Study was performed on dark control and photolytic exposed sample in a way to get the minimum exposure of 1.2 million lux hours for light and $200 \mathrm{~W} \mathrm{~h} / \mathrm{m}^{2}$ for ultraviolet region.

\section{Degradation of commercial eye drops sample solution}

The degradation of commercial eye drops sample solution was performed under the same above-mentioned stress conditions as the stock solution, including thermolytic, photolytic, acid, base hydrolytic and oxidative stress conditions.

\section{Abbreviations}

HPLC: High performance liquid chromatography; DE: Degradation products.

\section{Competing interests}

The authors declare that they have no competing interests.

\section{Authors' contributions}

$\mathrm{TMH}$ : Participate in method development and optimization, perform the experiments for forced degradation studies, collect experimental data and write the manuscript. ZJC: Propose and supervise the implementation of various experiments and write the manuscript. NZC, DLW and YHL: Participate in the experiments for method validation. All authors read and approved the final manuscript.

Received: 23 September 2013 Accepted: 27 January 2014

Published: 1 February 2014

\section{References}

1. Parente $G$, Pazzaglia M, Vincenzi $C$, Tosti A: Contact dermatitis from pheniramine maleate in eye drops. Contact Dermat 1999, 40:338-338.

2. Greiner JV, Udell IJ: A comparison of the clinical efficacy of pheniramine maleate/naphazoline hydrochloride ophthalmic solution and olopatadine hydrochloride ophthalmic solution in the conjunctival allergen challenge model. Clin Ther 2005, 27:568-577.

3. Karaman K, Bostanci EB, Aksoy E, Ulas M, Yigit T, Erdemli MO, Ercin U, Bilgihan A, Saydam G, Akoglu M: Effects of dexamethasone and pheniramine hydrogen maleate on stress response in patients undergoing elective laparoscopic cholecystectomy. Am J Surg 2013, 205:213-219.

4. Melouna M, Syrovy T, Vrana A: The thermodynamic dissociation constants of ambroxol, antazoline, naphazoline, oxymetazoline and ranitidine by the regression analysis of spectrophotometric data. Talanta 2004, 62:511-512.

5. Raghu MS, Basavaiah K, Ramesh PJ, Abdulrahman SAM, Vinay KB: Development and validation of a uv-spectrophotometric method for the determination of pheniramine maleate and its stability studies. $J \mathrm{Appl}$ Spectrosc 2012, 79:131-138.

6. Subramaniyan SP, Das SK: Rapid identification and quantification of chlorpheniramine maleate or pheniramine maleate in pharmaceutical preparations by thin-layer chromatography-densitometry. J AOAC Int 2004, 87:1319-1322.

7. Elgizawy SM, AhmeD AEHN: High-performance liquid-chromatographic determination of mepyramine maleate, pheniramine maleate and phenylpropanolamine hydrochloride in tablets and drops. Analyst 1987, 112:867-869.

8. Peralta CM, Silva RA, Fernandez LP, Masi AN: Online naphazoline quality control by micellar-enhanced spectrofluorimetry. Lumi 2011, 26:689-695.

9. Goicoechea $\mathrm{H}$, Olivieri A: Chemometric assisted simultaneous spectrophotometric determination of four-component nasal solutions with a reduced number of calibration samples. Anal Chim Acta 2002, 453:289-300.

10. Souri $E$, Amanlou M, Farsam $H$, Afshari A: A rapid derivative spectrophotometric method for simultaneous determination of naphazoline and antazoline in eye drops. Chem Pharm Bull 2006, 54:119-122

11. Massaccesi M: Gas-chromatographic determination of some imidazolines in pharmaceutical preparations through the use of the FFAP stationary phase. Pharm Acta Helv 1987, 62:302-305.

12. Santoni G, Medica A, Gratteri P, Furlanetto S, Pinzauti S: High-performance liquid-chromatographic determination of benzalkonium and naphazoline or tetrahydrozoline in nasal and ophthalmic solutions. Farmaco 1994, 40:751-754.

13. Ruckmick SC, Marsh DF, Duong DT: Synthesis and identification of the primary degradation product in a commercial ophthalmic formulation using $\mathrm{nmr}$, ms, and a stability-indicating hplc method for antazoline and naphazoline. J Pharm Sci 1995, 84:502-507.

14. Bauer J, Krogh S: High-performance liquid-chromatographic stabilityindicating assay for naphazoline and tetrahydrozoline in ophthalmic preparations. J Pharm Sci 1983, 72:1347-1349.

15. Chocholous P, Satınsky D, Solich P: Fast simultaneous spectrophotometric determination of naphazoline nitrate and methylparaben by sequential injection chromatography. Talanta 2006, 70:408-413.

16. Lemus Gallego JM, Perez Arroyo J: Determination of prednisolone, naphazoline and phenylephrine local pharmaceutical preparations by micellar electrokinetic chromatography. J Sep Sci 2003, 26:947-952.

17. Marchesini AF, Williner MR, Mantovani VE, Robles JC, Goicoechea HC: Simultaneous determination of naphazoline, diphenhydramine and 
phenylephrine in nasal solutions by capillary electrophoresis. J Pharm Biomed Anal 2003, 31:39-46.

18. Lemus Gallego JM, Perez Arroyo J: Determination of prednisolone and the most important associated compounds in ocular and cutaneous pharmaceutical preparations by micellar electrokinetic capillary chromatography. J Chromatogr B 2003, 784:39-47.

19. Khalil S: Analytical application of atomic emission and atomic absorption spectrometry for the determination of imidazoline derivatives based on formation of ion associates with sodium cobaltinitrite and potassium ferricyanide. Mikrochim Acta 1999, 130:181-184.

20. Ghoreishi SM, Behpour M, Nabi M: A novel naphazoline-selective membrane sensor and its pharmaceutical applications. Sens Actuators $B$ Chem 2006, 113:963-969.

21. Casado-Terrones S, Fernandez-Sanchez JF, Canabate Diaz B, Segura Carretero A, Fernandez-Gutierrez A: A fluorescence optosensor for analyzing naphazoline in pharmaceutical preparations-Comparison with other sensors. J Pharm Biomed Anal 2005, 38:785-789.

22. Diaz BC, Terrones SC, Carretero AS, Fernández JM, Gutiérrez AF: Comparison of three different phosphorescent methodologies in solution for the analysis of naphazoline in pharmaceutical preparations. Anal Bioanal Chem 2004, 379:30-34.

23. ICH (Q2B): Note for Guidance on Validation of Analytical Procedures: Methodology. Geneva: International conference on Harmonization, IFPMA; 1996.

24. Razzaq SN, Khan IU, Mariam I, Razzaq SS: Stability indicating HPLC method for the simultaneous determination of moxifloxacin and prednisolone in pharmaceutical formulations. Chem Cent J 2012, 6:94-103.

25. ICH (Q1A): Stability Testing of New Drug Substances and Products. Geneva: International Conference on Harmonization, Switerland; 2003.

26. ICH (Q1B): Photostability Testing on New Drug Substances and Products. Geneva: International Conference on Harmonization, Switerland; 1996.

doi:10.1186/1752-153X-8-7

Cite this article as: Huang et al:: A validated stability-indicating HPLC method for the simultaneous determination of pheniramine maleate and naphazoline hydrochloride in pharmaceutical formulations.

Chemistry Central Journal 2014 8:7.

\section{Publish with ChemistryCentral and every scientist can read your work free of charge \\ "Open access provides opportunities to our colleagues in other parts of the globe, by allowing anyone to view the content free of charge." \\ W. Jeffery Hurst, The Hershey Company. \\ - available free of charge to the entire scientific community \\ - peer reviewed and published immediately upon acceptance \\ - cited in PubMed and archived on PubMed Central \\ - yours - you keep the copyright \\ Submit your manuscript here: \\ http://www.chemistrycentral.com/manuscript/<smiles>c1ccccc1</smiles> \\ Chemistry Central}

